\title{
Assessment of Helicopter Pilot-in-the-Loop Models
}

\author{
Massimo Gennaretti, Federico Porcacchia, Simone Migliore, and Jacopo Serafini \\ Department of Engineering, Roma Tre University, Rome, Italy
}

Correspondence should be addressed to Massimo Gennaretti; massimo.gennaretti@uniroma3.it

Received 29 December 2016; Revised 27 February 2017; Accepted 8 March 2017; Published 27 April 2017

Academic Editor: Christopher J. Damaren

Copyright (C) 2017 Massimo Gennaretti et al. This is an open access article distributed under the Creative Commons Attribution License, which permits unrestricted use, distribution, and reproduction in any medium, provided the original work is properly cited.

\begin{abstract}
The aim of this paper is the evaluation of several pilot models found in the literature, suited for helicopter pilot-assisted and pilot-induced oscillations analyses. Three main topics are discussed: (i) sensitivity of rotorcraft-pilot couplings simulations on the application of the different pilot models available in the literature; (ii) effect of vehicle modeling on active pilot modeling; (iii) effects of interactions between active and passive pilot models. The focus is on hovering flight, where a specific adverse rotorcraft-pilot coupling phenomenon, the vertical bounce, may occur. Pilot models are coupled with a comprehensive aeroservoelastic model of a mid-weight helicopter. The numerical investigations are performed in frequency domain, in terms of eigenanalysis and frequency response analysis.
\end{abstract}

\section{Introduction}

Machine-pilot couplings are a wide class of phenomena potentially affecting every sort of vehicle, with consequences that may vary from discomfort to severe accidents. While being well documented in aeronautics (where they are usually called aircraft-pilot couplings, APC) since the beginning of the twentieth century [1], they were often ascribed to pilot faults, due to both lack of preparation or incorrect evaluation. Consequently, they received limited attention, mostly during training, when the pilot was instructed to perform particular actions, like to release controls, if an anomalous aircraft behavior was arising. On the contrary, APCs have been ignored during design process for decades. The result was a number of accidents (even recently, like that on the Japan Airlines flight JAL $706[2,3]$, in 1997) that has been reported as inability of the pilot to deal with unexpected aircraft oscillations (in that case arising when he took controls without disengaging the autopilot).

However, in the last decades, the scientific and technical communities have become more conscious about the importance of considering pilot and aircraft as a whole, in order to avoid such, potentially catastrophic, phenomena. In that sense, the role of the pilot in their insurgency has been partially reduced, while more attention has been devoted to the assessment of the conditions under which the aircraft-pilot coupling may yield undesired aircraft response. APC events have been defined alternatively as "involuntary trajectories and flight behaviors originating from an anomalous interaction between the pilot and the aircraft" or as "pilot-in-theloop instabilities" [4], in both cases remarking the need of an active, though not necessarily voluntary, pilot participation. The attention devoted to APCs has allowed the identification of undiscovered potential instabilities in some cases related to dynamics traditionally considered stable. As an example, it has been observed that the short-period mode damping may consistently drop in presence of pilot in the loop [5].

Additional challenges in the analysis of human-vehicle interaction arise nowadays, mostly due to the increased presence of flight control systems in modern aircraft. Acting in parallel or in series with the pilot, they may lose effectiveness or become source of instabilities if their interaction with him is not carefully assessed during the design phase.

Although cases of rotorcraft-pilot couplings (RPCs) are reported since World War II [6], studies on RPC have lagged about thirty years with respect to fixed-wing counterpart, the pioneering works of Mayo [7] and Pharam [8,9] being dated back to the last decade of the twentieth century. This fact, combined with the greater proneness of rotorcraft to instabilities, results in a wider area of relatively unexplored 

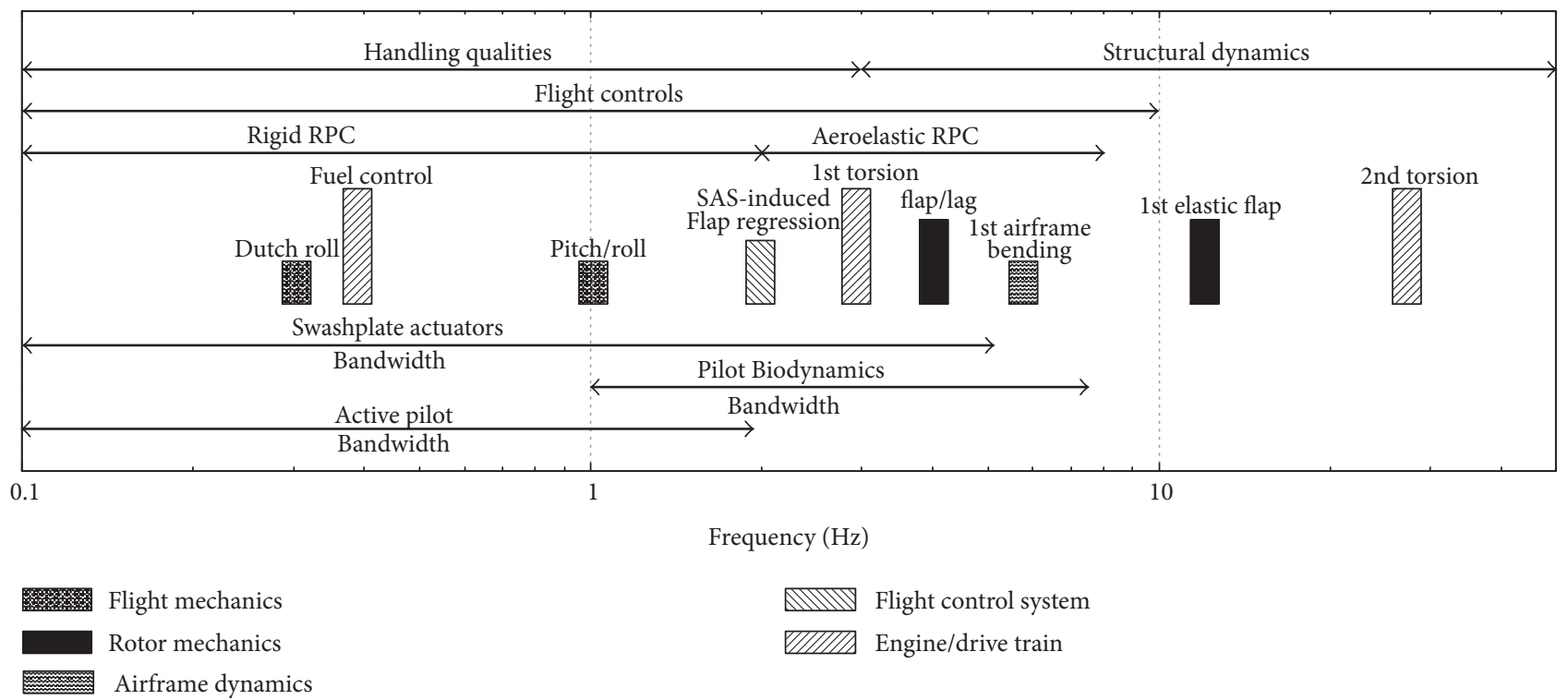

FIGURE 1: Typical rotorcraft frequencies (adapted from [23]).

research. In the last years, the EC-funded FP7 research project ARISTOTEL has been mainly focused on the analysis of RPCs insurgency and on means for their prevention. In that activity, the authors have been mostly involved in the assessment of aeroelastic triggers of RPCs, with particular emphasis on main rotor-airframe aeroelastic coupling [10-14].

Nevertheless, pilot modeling is still an open issue, usually addressed by separating active (voluntary, behavioral, and low-frequency) actions [15-17] from passive (involuntary, biodynamic, and mid-frequency) actions [7-9, 18-21], following the classification developed for fixed-wing aircraft. As a consequence, active pilot operations are more related to flight dynamics response phenomena, while passive pilot actions couple with aeroelastic responses.

The objective of the present work is the assessment of the following issues regarding pilot-in-the-loop rotorcraft response and stability analyses: (i) RPCs simulations sensitivity on the application of the different pilot models available in the literature; (ii) effect of vehicle modeling on active pilot modeling; (iii) effects of interactions between active-passive pilot models.

\section{Rotorcraft-Pilot Coupling Classification}

The RPC study requires competence in the modeling of several subsystems. Indeed, several different helicopter dynamics phenomena occur in the frequency range where RPCs events take place (as shown in Figure 1 for a medium-weight vehicle). These, combined with voluntary and involuntary pilot actions, leads to the definition of two main different kinds of RPCs: the so-called pilot-induced oscillations (or rigid-body RPCs), which are mostly related to active piloting and rigid-body dynamics, and the pilot-assisted oscillations (or aeroelastic RPCs) characterized by the involuntary feedback on controls due to cabin vibrations and mostly involving aeroelasticity and structural dynamics. The former involve events in the frequency range from 0 to $2 \mathrm{~Hz}$, while the latter occur in the frequency range from 2 to $8 \mathrm{~Hz}$ (above, both pilot biodynamics and controls actuator responses become negligible).

It is worth noting that this separation is quite arbitrary, since an overlap between active and passive pilot behavior exists. Moreover, unlike in the fixed-wing case, aeroelastic effects usually play a crucial role in rotorcraft flight dynamics, primarily due to the low-frequency main rotor deformation. However, the $2 \mathrm{~Hz}$ boundary is commonly accepted as valid from both the aeromechanics and the biodynamics point of view.

Another commonly used classification derived from fixed-wing field is that discerning the characteristic of the dynamics driving a RPC phenomenon and its trigger. Category I RPCs are caused by linear dynamics, while strong nonlinearities (e.g., control saturations) determine categories II and III (in the latter, an external trigger like malfunctioning, gust, or pilot task is required). Finally, an informal category IV often overlapping with PAOs is associated with RPCs characterized by significant elastic deformations. While cat. I phenomena are usually investigated through eigenanalysis, cat. II and III require specific techniques (typically in the time domain) [4]. Cat. IV RPCs may be approached in different ways depending on the characteristics of the system: thus far, most of the analyses have been limited to linearizable systems, thus exploiting eigenanalysis (see, e.g., the investigation on vertical bouncing described in [11]).

Control designers have identified a number of retrofit solutions to alleviate RPCs, usually consisting of the introduction of small friction on controls. At the same time, the pilot community has identified piloting procedures to deal with specific RPCs. In the case of vertical bouncing, an instable loop involving collective control, main rotor coning, and vertical motion of pilot seat (see Figure 2), the procedure simply consists of loosening the grasp of the hand on the collective 


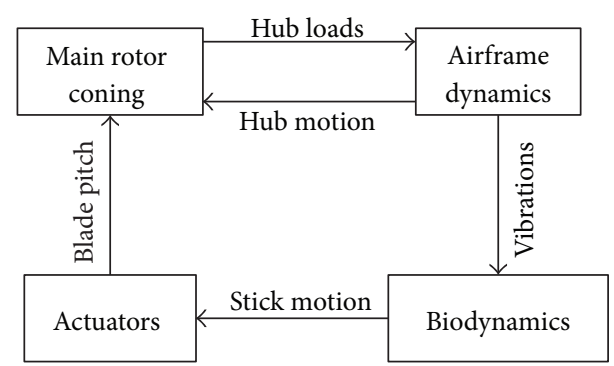

FIgURE 2: Vertical bouncing loop.

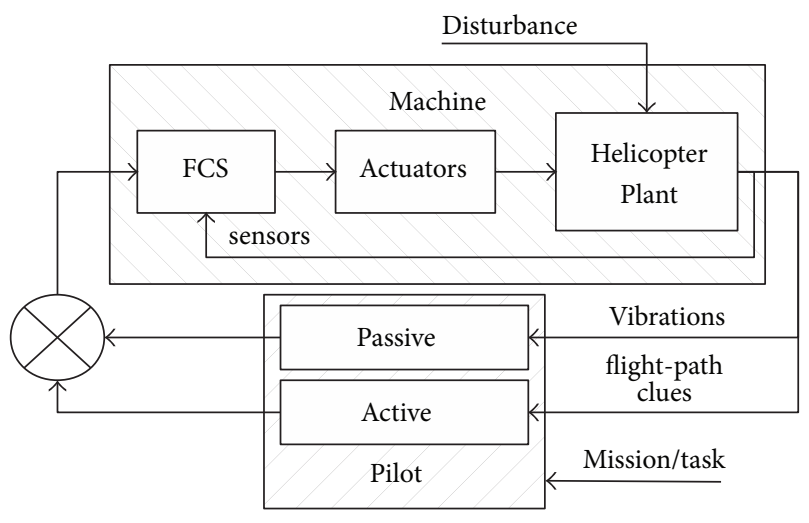

FIGURE 3: Pilot-in-the-loop representation.

lever, weakening the feedback. It is however evident that the capability to predict potential adverse couplings between pilot and aircraft since the design phase would represent a great advantage in the production of safer helicopters.

\section{Pilot Modeling}

A schematic representation of the pilot-in-the-loop system is shown in Figure 3. The pilot action is modeled as the combination of active and passive behavior, both given as feedback to the machine response. The commands exerted by the pilot (both voluntarily and involuntarily) are processed by FCSs (if present) and executed by actuators. These produce loads and consequently vibrations and rigid-body motion which, in turn, force pilot dynamics. Note that the inputs to the whole system are the specific mission/task to be performed and potential external disturbances.

In the following, a review of the pilot models used in this work is outlined.

3.1. Passive Pilot Modeling. Involuntary pilot actions on controls are determined by the complex dynamics of pilot body (including bones, muscles, and articulations) in response to the vibration transmitted from seat and controls. The most common approach to introduce passive pilot modeling in the loop is the use of transfer functions (usually of singleinput/single-output type) between seat and control sticks motion. These are often determined with experimental campaigns, using a shaker to force the seat and measuring stick displacement $[7,8]$ for a number of pilots. While the fidelity of these tests may be increased by positioning the pilot in a simulator with a realistic cockpit and visual feedback, it has been demonstrated that the response is heavily influenced by several factors. The most important of them are (i) pilot physical characteristics (weight, height, and tonus) [7, 19]; (ii) cockpit configuration; and (iii) piloting task. In order to deal with these issues, some authors proposed the direct biodynamic modeling through a multibody analysis [22], while others focused their work on the influence of workload on pilot response [20]. However, due to the variability of pilot skills and characteristics and of piloting tasks, a reliable and practical approach to RPCs should include statistical considerations to model those uncertainties.

Below, several passive pilot models proposed in literature are briefly outlined. They are all presented in terms of transfer functions between seat acceleration, $a_{s}$, and stick rotation, $\alpha$, namely,

$$
H(s)=\frac{\widetilde{\alpha}}{\widetilde{a}_{s}} .
$$

Note that the number and position of poles and zeros of transfer functions change with the considered model.

\subsubsection{Pilots Acting on Collective Control}

Mayo's Transfer Function. In Mayo's experiment [7], the collective stick motion was recorded while the seat was perturbed using vertical, sinusoidal acceleration disturbances at frequencies ranging from $1 \mathrm{~Hz}$ to $5 \mathrm{~Hz}$. The acceleration of pilot's wrist was recorded using three-axis accelerometers, which were mounted on the collective grip, in a classical configuration cockpit of helicopter. The experiment was performed in an open-loop way, in that the control input provided by the pilot did not affect the acceleration of the motion platform. In order to characterize the influence of the pilot body, mesomorphic (larger size) and ectomorphic (smaller size) test pilots were considered.

The following 4-poles and 2-zeros transfer functions were identified:

$$
\begin{aligned}
& H_{\text {ecto }}=\frac{G}{r_{\text {st }}} \frac{1}{\left(s-p_{1}\right)\left(s-p_{2}\right)} \frac{-s^{2}-8.51 s}{s^{2}+13.70 s+452.3}, \\
& H_{\text {meso }}=\frac{G}{r_{\text {st }}} \frac{1}{\left(s-p_{1}\right)\left(s-p_{2}\right)} \frac{-s^{2}-9.29 s}{s^{2}+13.31 s+555.4},
\end{aligned}
$$

where $r_{\text {st }}$ is the length of the collective lever and $p_{1}$ and $p_{2}$ are two pseudointegrators (usually set to $1 \mathrm{~Hz}$ in order to avoid nonphysical behavior at low frequency [11]), while $G$ depends on the reference position of collective lever, as shown in Figure 4.

Practical Biodynamic Feedthrough Models. These transfer functions, proposed in [20], provide enhanced BDFT rotorcraftpilot models of increased accuracy and complexity equivalent to Mayo's one. The main improvements concern the extended model frequency range and the inclusion of both the somatotype effect and the effect of task difficulty on neuromuscular admittance. Also the influence of the subject 


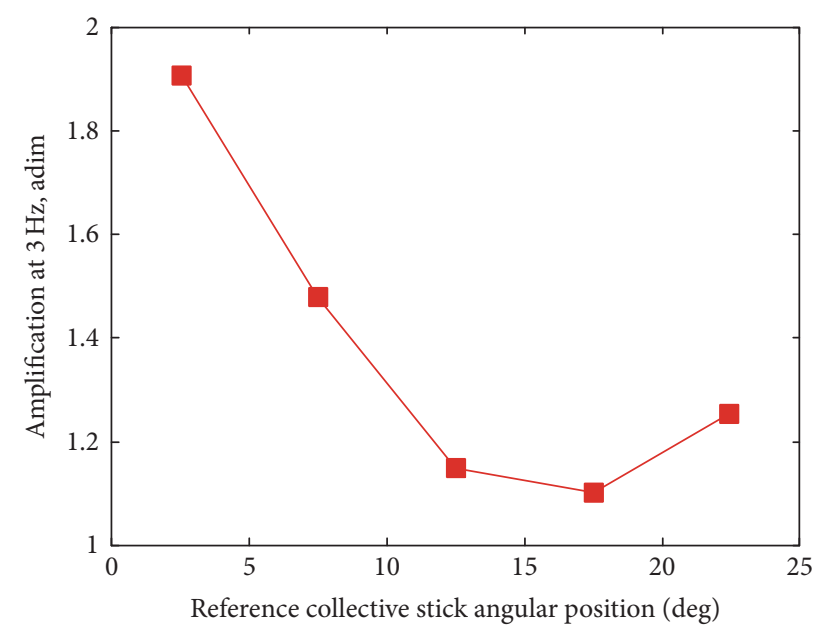

FIGURE 4: Influence of reference arm position on pilot transfer function.

variability is included. The data have been obtained by an experimental campaign exploiting the 6-DOF SIMONA Research Simulator at Delft University of Technology. In the tests, acceleration and force disturbances have been applied to the control devices. The subjects were instructed to perform three disturbance rejection tasks, namely, position task, relax task, and force task.

The first task consisted in resisting the force perturbations as much as possible, while maintaining the reference position of the collective lever; for the relax task it was required to relax the arms and passively undergo the perturbations, whereas in the last task the pilot was instructed to minimize the force applied to the collective lever, yielding to the perturbation force as much as possible [20]. In these experiments, the angle of deflection of collective lever and the applied force at the inceptor were measured. In order to characterize the bandwidth of the pilot, the $0.05-21.5 \mathrm{~Hz}$ frequency range was considered for vertical force and acceleration disturbances, actually extending that of Mayo's experiments $(1-5 \mathrm{~Hz})$.

The following three passive pilot transfer functions have been identified by the described BDFT modeling effort:

$$
\begin{aligned}
& H_{\mathrm{BDFT}}^{\mathrm{FT}}=\frac{1}{0.7 s(s+3.26)}\left(\frac{554.00}{s^{2}+18.00 s+550.36}-1\right), \\
& H_{\mathrm{BDFT}}^{\mathrm{RT}}=\frac{1}{0.7 s(s+5.06)}\left(\frac{597.00}{s^{2}+17.23 s+599.81}-1\right), \\
& H_{\mathrm{BDFT}}^{\mathrm{PT}}=\frac{1}{0.7 s(s+5.57)}\left(\frac{447.56}{s^{2}+8.28 s+446.42}-1\right) .
\end{aligned}
$$

Bibby Transfer Functions. Further passive pilot models have been identified experimentally at the University of Liverpool's Bibby flight simulation laboratory, using a visual channel flight simulator mounted upon a six-axis motion [24]. The human subject was seated in the simulator cockpit with MTx motion sensors attached near to the wrist and the elbow. Because, ideally, most of the tests required the collective lever forces to be null, the collective lever friction was set to the
TABLE 1: Poles, zeros, and gains of transfer functions identified at the Bibby flight simulation laboratory.

\begin{tabular}{lcccc}
\hline Pilot & Pole \#1 & Pole \#2 & Zero & Gain \\
\hline \multirow{2}{*}{ \#1, 10\% } & $9.8189 \pm$ & $7.0661 \pm$ & $2.6282 \pm$ & -12.446 \\
& $20.4374 i$ & $31.2961 i$ & $28.3482 i$ & \\
$\# 1,50 \%$ & $6.6574 \pm$ & $4.9026 \pm$ & $3.5630 \pm$ & -6.86 \\
& $19.3086 i$ & $35.8785 i$ & $27.6716 i$ & \\
$\# 1,90 \%$ & $4.6876 \pm$ & $3.5824 \pm$ & $7.3902 \pm$ & -2.842 \\
& $15.3775 i$ & $36.1740 i$ & $27.8659 i$ & \\
$\# 2,10 \%$ & $12.2048 \pm$ & $5.0502 \pm$ & $3.2423 \pm$ & -12.348 \\
& $19.8534 i$ & $33.7910 i$ & $30.9463 i$ & \\
$\# 2,50 \%$ & $5.9031 \pm$ & $7.7169 \pm$ & $5.7946 \pm$ & -6.468 \\
& $16.9689 i$ & $38.3072 i$ & $24.1660 i$ & \\
$\# 2,90 \%$ & $1.9331 \pm$ & $6.1569 \pm$ & $6.5938 \pm$ & -3.332 \\
& $12.6278 i$ & $37.2060 i$ & $18.3922 i$ & \\
\hline
\end{tabular}

minimum available. A display was created with indication of the position of the control inceptors, in order to avoid drift phenomena due to the lack of feedback to the occupant. The controls (longitudinal and lateral cyclic stick, collective lever, and rudder pedals) were set to their nominal start positions and three reference positions of collective lever have been investigated (10\%, 50\%, and $90 \%$ of the full scale deflection). Axis excitation was a sinusoidal frequency sweep starting at $0.4 \mathrm{~Hz}$ that steps up in $0.2 \mathrm{~Hz}$ increments to the final value of $7 \mathrm{~Hz}$. Also in this case a single-input/single-output (SISO) model has been identified, with the transfer function provided in the following zeros-poles form:

$$
H_{\text {Bibby }}=G \frac{(s-Z)\left(s-Z^{*}\right)}{\left(s-P_{1}\right)\left(s-P_{1}^{*}\right)\left(s-P_{2}\right)\left(s-P_{2}^{*}\right)} \text {, }
$$

characterized by a fourth-order denominator and a secondorder numerator (deriving from two pairs of complex conjugated poles and one pair of complex conjugated zeros). $G$ is a gain dependent on the reference arm position. The identified values of $G, P_{1}, P_{2}$, and $Z$ for two pilots for three reference positions of the collective lever are reported in Table 1.

Pilot Modeling for Aeroservoelastic RPC in ARISTOTEL. During ARISTOTEL European FP7 Research Project several BDFT tests have been conducted by the flight simulator at University of Liverpool [19], in order to identify pilots biodynamic response while being subject to vertical and lateral acceleration. The excitation consisted of colored noise signals, band-pass-filtered between 1 and $10 \mathrm{~Hz}$, with zero mean value and $0.004 \mathrm{~g} \mathrm{rms}$.

The motion induced to the control inceptors by the oscillations imposed to the cockpit was measured, along with the motion induced to the limbs. No specific flight task was required, the occupant being requested to hold the controls without compensating the stick vibrations and to maintain the collective lever in the proximity of the reference position to avoid excessive drift. Also in this case the pilot has been considered as a SISO system (vertical acceleration as input and wrist acceleration as output). 
TABLE 2: Coefficients of collective control transfer functions identified in ARISTOTEL.

\begin{tabular}{|c|c|c|c|c|c|c|c|}
\hline & & $n_{5}$ & $n_{4}$ & $n_{3}$ & $n_{2}$ & $n_{1}$ & $n_{0}$ \\
\hline Berryman 1 & & 0 & 0 & $-5.53 \cdot 10^{3}$ & $3.34 \cdot 10^{5}$ & $-1.03 \cdot 10^{7}$ & $8.49 \cdot 10^{8}$ \\
\hline Berryman 2 & & $-5.02 \cdot 10^{1}$ & $2.40 \cdot 10^{3}$ & $-1.55 \cdot 10^{5}$ & $8.72 \cdot 10^{6}$ & $3.02 \cdot 10^{6}$ & $4.94 \cdot 10^{9}$ \\
\hline Berryman 3 & & $-2.01 \cdot 10^{1}$ & $3.94 \cdot 10^{2}$ & $-2.12 \cdot 10^{4}$ & $1.47 \cdot 10^{6}$ & $3.53 \cdot 10^{7}$ & $6.82 \cdot 10^{8}$ \\
\hline Berryman 4 & & $-5.27 \cdot 10^{1}$ & $2.29 \cdot 10^{3}$ & $-1.18 \cdot 10^{5}$ & $8.84 \cdot 10^{6}$ & $3.32 \cdot 10^{7}$ & $5.22 \cdot 10^{9}$ \\
\hline Berryman 5 & & $-6.13 \cdot 10^{2}$ & $3.03 \cdot 10^{4}$ & $-1.82 \cdot 10^{6}$ & $1.08 \cdot 10^{8}$ & $2.80 \cdot 10^{8}$ & $6.61 \cdot 10^{10}$ \\
\hline Berryman6 & & $-1.02 \cdot 10^{2}$ & $3.95 \cdot 10^{3}$ & $-1.05 \cdot 10^{5}$ & $1.61 \cdot 10^{7}$ & $1.07 \cdot 10^{8}$ & $1.00 \cdot 10^{10}$ \\
\hline Mayer 1 & & & $2.11 \cdot 10^{3}$ & $3.34 \cdot 10^{4}$ & $1.28 \cdot 10^{7}$ & $1.26 \cdot 10^{8}$ & $1.25 \cdot 10^{10}$ \\
\hline Mayer 2 & & & $1.32 \cdot 10^{2}$ & $3.57 \cdot 10^{3}$ & $8.75 \cdot 10^{5}$ & $1.43 \cdot 10^{7}$ & $1.08 \cdot 10^{9}$ \\
\hline Cheyne & & & $1.36 \cdot 10^{3}$ & $4.30 \cdot 10^{4}$ & $6.04 \cdot 10^{6}$ & $9.13 \cdot 10^{7}$ & $2.73 \cdot 10^{9}$ \\
\hline & $d_{6}$ & $d_{5}$ & $d_{4}$ & $d_{3}$ & $d_{2}$ & $d_{1}$ & $d_{0}$ \\
\hline Berryman 1 & & 1. & $2.88 \cdot 10^{2}$ & $1.93 \cdot 10^{4}$ & $1.17 \cdot 10^{6}$ & $2.82 \cdot 10^{7}$ & $8.75 \cdot 10^{8}$ \\
\hline Berryman 2 & 1. & $1.61 \cdot 10^{2}$ & $1.08 \cdot 10^{4}$ & $4.60 \cdot 10^{5}$ & $1.61 \cdot 10^{7}$ & $2.54 \cdot 10^{8}$ & $4.94 \cdot 10^{9}$ \\
\hline Berryman 3 & 1. & $6.42 \cdot 10^{1}$ & $4.75 \cdot 10^{3}$ & $1.61 \cdot 10^{5}$ & $4.99 \cdot 10^{6}$ & $7.66 \cdot 10^{7}$ & $7.07 \cdot 10^{8}$ \\
\hline Berryman 4 & 1. & $1.73 \cdot 10^{2}$ & $1.11 \cdot 10^{4}$ & $4.97 \cdot 10^{5}$ & $1.70 \cdot 10^{7}$ & $2.84 \cdot 10^{8}$ & $5.3 \cdot 10^{9}$ \\
\hline Berryman 5 & 1. & $1.59 \cdot 10^{3}$ & $1.06 \cdot 10^{5}$ & $5.36 \cdot 10^{6}$ & $1.95 \cdot 10^{8}$ & $3.38 \cdot 10^{9}$ & $6.62 \cdot 10^{10}$ \\
\hline Berryman6 & 1. & $2.72 \cdot 10^{2}$ & $1.74 \cdot 10^{4}$ & $8.24 \cdot 10^{5}$ & $2.9 \cdot 10^{7}$ & $5.03 \cdot 10^{8}$ & $1.00 \cdot 10^{10}$ \\
\hline Mayer 1 & 1. & $7.4 \cdot 10^{1}$ & $9.45 \cdot 10^{3}$ & $3.59 \cdot 10^{5}$ & $2.17 \cdot 10^{7}$ & $3.5 \cdot 10^{8}$ & $1.26 \cdot 10^{10}$ \\
\hline Mayer 2 & & 1. & $2.95 \cdot 10^{2}$ & $1.21 \cdot 10^{4}$ & $1.25 \cdot 10^{6}$ & $2 . \cdot 10^{7}$ & $1.07 \cdot 10^{9}$ \\
\hline Cheyne & 1. & $7.68 \cdot 10^{1}$ & $7.1 \cdot 10^{3}$ & $2.55 \cdot 10^{5}$ & $9.84 \cdot 10^{6}$ & $1.54 \cdot 10^{8}$ & $2.73 \cdot 10^{9}$ \\
\hline
\end{tabular}

Pilot transfer functions have been determined in a rational polynomial form of the type

$$
H_{A}=\frac{1}{r_{\text {st }}\left(s-p_{1}\right)\left(s-p_{2}\right)}\left(\frac{n_{5} s^{5}+\cdots+n_{0}}{d_{6} s^{6}+\cdots+d_{0}}-1\right) .
$$

In Table 2 the transfer function coefficients identified for each pilot/test examined are presented (pseudointegrator poles, $p_{1}$ and $p_{2}$, are set equal to $1 \mathrm{~Hz}$ ).

Analyzing these transfer functions, it is possible to infer that there are significantly damped biodynamic poles in the range between 3 and $10 \mathrm{~Hz}$. Even for the same pilot, different tests are characterized by different responses. It is worth underlining that it seems impossible to clearly distinguish professional from nonexpert pilot behavior and that there is no clear dependence on biometric measures.

\subsubsection{Pilots Acting on Cyclic Control}

Parham Lateral and Longitudinal Transfer Functions. An aeroelastic analysis with longitudinal/lateral pilot in the loop has been performed by Parham [8], using data from the Osprey V-22 flight test program. The initial pilot model used in that analysis was a math model, relating the pilot lateral stick displacement expressed in inches, with lateral acceleration of pilot seat, measured in $\mathrm{g}$. It has been refined and validated by examination of several sets of flight test data, as well as measured outputs from shake tests with pilot holding the controls. Several tests revealed a large variation of responses from different pilots and also a strongly nonlinear behavior. The following transfer functions, respectively, for lateral and longitudinal passive pilot models relating cyclic stick rotation to seat acceleration (expressed in $\mathrm{m} / \mathrm{s}^{2}$ ) have been finally determined as an optimal fit of the large amount of responses examined:

$$
\begin{gathered}
H_{P_{\text {lat }}}(s)=\frac{0.0254}{9.81 r_{\text {cyc }}} \\
\cdot \frac{9.4487 \cdot 10^{3} s-2.8526 \cdot 10^{5}}{s^{3}+1.2641 \cdot 10^{3} s^{2}+9.7102 \cdot 10^{3} s+3.8554 \cdot 10^{5}}, \\
H_{P_{\text {lon }}}(s)=\frac{0.0254}{9.81 r_{\mathrm{cyc}}} \\
\cdot \frac{-9.0227 \cdot 10^{3} s^{2}+1.4602 \cdot 10^{4} s+5.7467 \cdot 10^{7}}{s^{4}+1308.5 s^{3}+75206 s^{2}+1.2590 \cdot 10^{7} s+3.0382 \cdot 10^{7}},
\end{gathered}
$$

where $r_{\text {cyc }}$ denotes the cyclic stick length.

Pilot Modeling for Aeroservoelastic RPC in ARISTOTEL. In the same experimental test campaign held at the University of Liverpool for the collective control passive pilot modeling (see Table 3), lateral control transfer functions have also been identified. Measured data revealed a good level of coherence between the lateral acceleration of the pilot seat and the lateral acceleration of the pilot wrist. Pilot's lateral responses have been fitted using a rational transfer function composed of a 6th-order polynomial denominator and 4thorder polynomial numerator, which reads

$$
H_{A_{\text {lat }}}=\frac{1}{r_{\mathrm{cyc}} s^{2}} \frac{n_{4} s^{4}+\cdots+n_{0}}{d_{6} s^{6}+\cdots+d_{0}} .
$$

In Table 3 the transfer function coefficients identified for each pilot/test examined are presented.

These transfer functions significantly depend on stiffness, damping, and mass of the control inceptors. In every transfer 
TABLE 3: Coefficients of lateral control transfer functions identified in ARISTOTEL.

\begin{tabular}{|c|c|c|c|c|c|c|c|}
\hline & & $n_{5}$ & $n_{4}$ & $n_{3}$ & $n_{2}$ & $n_{1}$ & $n_{0}$ \\
\hline Berryman 1 & & -2.73 & $-1.55 \cdot 10^{1}$ & $1.26 \cdot 10^{4}$ & $-1.64 \cdot 10^{5}$ & $4.4 \cdot 10^{6}$ & $5.40 \cdot 10^{7}$ \\
\hline Berryman2 & & 0 & $-2.91 \cdot 10^{2}$ & $1.53 \cdot 10^{4}$ & $-2.48 \cdot 10^{5}$ & $3.25 \cdot 10^{6}$ & $4.33 \cdot 10^{7}$ \\
\hline Mayer 1 & & 0 & 0 & -2.00 & $7.41 \cdot 10^{2}$ & $8.03 \cdot 10^{3}$ & $4.29 \cdot 10^{5}$ \\
\hline Mayer 2 & & 0 & 0 & $1.59 \cdot 10^{1}$ & $3.02 \cdot 10^{2}$ & $5.58 \cdot 10^{3}$ & $2.86 \cdot 10^{4}$ \\
\hline Cheyne1 & & $1.78 \cdot 10^{1}$ & $-1.12 \cdot 10^{3}$ & $3.23 \cdot 10^{4}$ & $-5.27 \cdot 10^{5}$ & $4.69 \cdot 10^{7}$ & $1.11 \cdot 10^{9}$ \\
\hline Cheyne2 & & $1.65 \cdot 10^{1}$ & $-1.05 \cdot 10^{3}$ & $2.75 \cdot 10^{4}$ & $-6.19 \cdot 10^{5}$ & $3.81 \cdot 10^{7}$ & $9.23 \cdot 10^{8}$ \\
\hline & $d_{6}$ & $d_{5}$ & $d_{4}$ & $d_{3}$ & $d_{2}$ & $d_{1}$ & $d_{0}$ \\
\hline Berryman 1 & 1 & $4.74 \cdot 10^{1}$ & $2.74 \cdot 10^{3}$ & $5.67 \cdot 10^{4}$ & $1.05 \cdot 10^{6}$ & $9.51 \cdot 10^{6}$ & $6 \cdot 10^{7}$ \\
\hline Berryman 2 & 1 & $4.2 \cdot 10^{1}$ & $2.54 \cdot 10^{3}$ & $4.89 \cdot 10^{4}$ & $9.15 \cdot 10^{5}$ & $7.86 \cdot 10^{6}$ & $4.86 \cdot 10^{7}$ \\
\hline Mayer 1 & 0 & 0 & 1 & $4.27 \cdot 10^{1}$ & $1.88 \cdot 10^{3}$ & $2.56 \cdot 10^{4}$ & $4.42 \cdot 10^{5}$ \\
\hline Mayer 2 & 0 & 0 & 1 & $2.66 \cdot 10^{1}$ & $5.55 \cdot 10^{2}$ & $6.04 \cdot 10^{3}$ & $3.37 \cdot 10^{4}$ \\
\hline Cheyne1 & 1 & $5.95 \cdot 10^{1}$ & $5.82 \cdot 10^{3}$ & $1.68 \cdot 10^{5}$ & $7.14 \cdot 10^{6}$ & $8.15 \cdot 10^{7}$ & $1.34 \cdot 10^{9}$ \\
\hline Cheyne2 & 1 & $5.66 \cdot 10^{1}$ & $4.87 \cdot 10^{3}$ & $1.46 \cdot 10^{5}$ & $5.31 \cdot 10^{6}$ & $6.69 \cdot 10^{7}$ & $1.07 \cdot 10^{9}$ \\
\hline
\end{tabular}

function there is one clear pair of dominant poles between 2 and $3 \mathrm{~Hz}$. These are less damped than in case of collective control transfer functions.

3.2. Active Pilot Modeling. Voluntary pilot actions on controls have been extensively investigated since the half of XX century. The pioneer of the so-called control-theoretic pilot models (namely, the models considering the pilot as a feedback to vehicle dynamics) was Tustin, who suggested the first transfer function representing the human operator [25]. Thirty years later, McRuer put the basis of manual control theory [15], highlighting the correlation between pilot transfer function and controlled object dynamics (in the next paragraph, the McRuer crossover model is described with some details).

In the following years, the crossover model has inspired several quasi-linear models, where nonlinearities are introduced with a residual term (see, e.g., [15, 26-28]). Research work has been focused also on the effect of task difficulty on nonlinearities of pilot response, as well as on detailed modeling of pilot neuromuscular, proprioceptive, and visual sensory characteristics (see, among others, $[29,30]$ ).

3.2.1. Crossover Model. The fundamentals of man-machine interaction theory were introduced by McRuer [15] during the 70s. His model starts from a simple consideration about human control from a skilled human on inanimate elements: when the stimulus forcing the system has random timestationary characteristics, the human operator adapts his strategy control with actions having the same random and time-stationary properties. The simplest manual control, called single loop compensatory system with visual stimulus, is shown in Figure 5.

The forcing input $i(t)$ is a random function with stationary or quasi-stationary properties. The compensatory display shows to the human operator only the visual stimulus $e(t)$ (tracking error) defined as the difference between the system output $m(t)$ and $i(t)$. Usually, the pilot's task is to minimize $e(t)$, trying to keep the indicator superimposed to a stationary point or line. The error minimization is achieved by pilot control action, $c(t)$. This compensatory model is the paradigm for
TABLE 4: Dynamics of controlled elements.

\begin{tabular}{lcc}
\hline Type & Equation of motion & Transfer function $Y_{c}(s)$ \\
\hline Proportional & $m(t)=K_{c} c(t)$ & $K_{c}$ \\
Rate of velocity & $\dot{m}(t)=K_{c} c(t)$ & $\frac{K_{c}}{s}$ \\
First-order lag & $\dot{m}(t)+a m(t)=K_{c} c(t)$ & $\frac{K_{c}}{s+a}$ \\
Acceleration & $\ddot{m}(t)=K_{c} c(t)$ & $\frac{K_{c}}{s^{2}}$ \\
\hline
\end{tabular}

much more complicated configurations as multiloop system with visual stimuli and the pursuit mode in which the perception of system state is the input to the pilot model.

In order to obtain a simple description of the active pilot's behavior, McRuer asserted that the operator action strongly depends on the dynamics of controlled elements. The simplified model of manual control system relates the human operator to controlled element dynamics by a simple equation. In the tests, several dynamic models were controlled by a single highly trained operator. Table 4 shows the most relevant cases.

These dynamics were chosen in that they are very simple and have many applications in practical control systems. The human transfer function modeling the pilot behavior, $Y_{p}(s)$, is different for each controlled element described by the transfer function, $Y_{c}(s)$, but the loop transfer function, $Y_{p}(s) \cdot Y_{c}(s)$, is essentially the same. Moving from these considerations, the following crossover law, relating the operator and the controlled element, is introduced:

$$
Y_{p}(s) Y_{c}(s) \doteq \frac{\omega_{c} e^{-s \tau_{e}}}{s} .
$$

The above relation states that the pilot-vehicle system in open-loop behaves as an integrator around the crossover region. The model does not distinguish explicitly between controlled element and operator characteristics, although it is evident that the two parameters, $\omega_{c}$ and $\tau_{e}$, depend on 

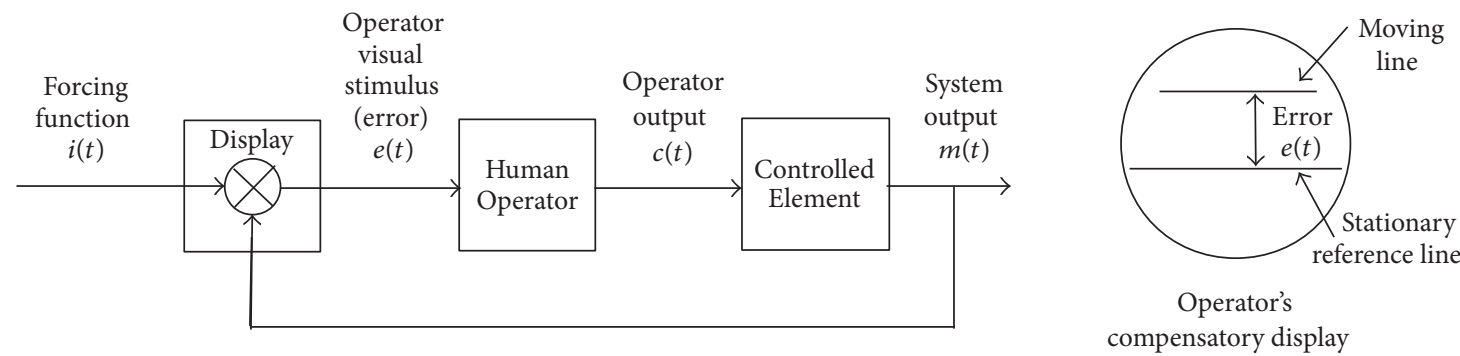

FIGURE 5: Single loop compensatory scheme. From [15].

controlled element dynamics, task variables, and other details which affect the operator.

A brief and intuitive interpretation of the crossover frequency can be made analyzing the closed-loop transfer function relating the input $\widetilde{i}(s)$ and the output $\widetilde{m}(s)$ that can be written as

$$
\frac{\widetilde{m}(s)}{\widetilde{i}(s)}=\frac{G(s)}{1+G(s)}=\frac{\omega_{c} e^{-s \tau}}{s+\omega_{c} e^{-s \tau}},
$$

where $G(s)=\omega_{c} e^{-s \tau} / s$. When $|G(s)| \gg 1$, then $\widetilde{m}(s) / \widetilde{i}(s) \rightarrow 1$, whereas when $|G(s)| \ll 1$, then $\widetilde{m}(s) / \widetilde{i}(s) \rightarrow G(s)$. At the same time, the transfer function relating the tracking error with the input signal, namely, $\widetilde{e}(s) \widetilde{i}(s)=1 /(1+G(s))$, tends to 0 when $|G(s)| \gg 1$, whereas it tends to 1 when $|G(s)| \ll$ 1. The most significant property of feedback systems is that when the open-loop transfer function $|G(s)|$ is much greater than 1 (low frequency) the closed-loop response becomes similar to the input, $\widetilde{m}(s) \approx \widetilde{i}(s)$, whereas when $|G(s)|$ tends to 0 (high frequency), the closed-loop transfer function approaches the open-loop one. The crossover frequency, $\omega_{c}$, defined as the intersection of the Bode diagram of $G(s)$ with the zero $\mathrm{dB}$ gain line divides the frequency range in two zones, defined as closed-loop behavior and no-feedback action. For stable applications the nondimensional parameter $\tau \omega_{c}$ ranges between 0 and $\pi / 2$, whereas $\omega_{c}$ ranges from 3 to $6 \mathrm{rad} / \mathrm{s}$, with a phase margin between $25^{\circ}$ and $45^{\circ}$.

\section{Results}

The helicopter model considered in the present numerical investigation is representative of a lightweight helicopter with a hingeless rotor design, loosely inspired by the Bo-105. Airframe structural dynamics, fuselage and tail rotor aerodynamics, and main rotor aeroelastic responses (based on flaplag-torsion blade dynamics) are modeled through a comprehensive aeromechanic formulation described in [11]. Suited transfer functions multiplied by the gearing ratio $G$ describe the control system dynamics [11].

The airframe elastic deformation is taken into account by four normal vibration modes, reported in Table 5 . The first mode involves significant bending of the airframe about the pitch axis, as well as out-of-phase relative vertical motion between the main rotor attachment and the cabin floor, thus possibly introducing nonnegligible interaction between the vertical oscillation of the rotorcraft and that of the pilot's seats.
TABle 5: Airframe modes.

\begin{tabular}{lc}
\hline Mode & Frequency $[\mathrm{Hz}]$ \\
\hline Tail boom vertical bending & 6. \\
Tail boom lateral bending & 8. \\
Fuselage vertical bending & 11.5 \\
Tail boom torsion & 12.5 \\
\hline
\end{tabular}

However, all mode shapes show some participation of hub and cabin floor displacements.

The model has been linearized about the trim state, obtaining a state space representation of the whole helicopter related to the entire set of aeroservoelastic states, and pilot control variables consisting of collective, longitudinal, and lateral cyclic pitches and tail rotor collective pitch $\left(\theta_{0}, \theta_{s}, \theta_{c}, \theta_{p}\right.$, resp.). A multiblade variable transformation [31] has been used to get a linear time invariant approximation of the system. Finally, the fully coupled system sketched in Figure 3 is obtained including active and passive pilot models in parallel feedback to the helicopter dynamics (in this paper, no FCS has been considered).

\subsection{Passive Pilot in the Loop}

Collective Pilot Model. First, the analysis of the influence on hovering helicopter stability of in-the-loop application of the different passive collective control pilot models examined in Section 3.1 has been performed. The results of this investigation are shown in Figures 6 and 7 (which is an enlargement of the former, for the region containing the aeroelastic poles most relevant for RPC), in terms of root locus determined by increasing the gearing ratio, $G$, from 0 (out-of-the-loop pilot) to 3 (this variation is represented by markers of decreasing size). Complementary information may be obtained from Figure 8 that, representing the areas delimited by the aeroelastic poles for $G=1,2,3$, gives an estimation of the scattering of helicopter poles with different pilots in the loop, for the same range of frequency of Figure 7.

It is worth noting that the different pilot models are not directly comparable, since some of them are obtained averaging on several subjects belonging to the same class (e.g., classes may be defined according to physical features, like Mayo's approach), while others are representative of the same subject in different operating conditions (for details, see Section 3.1). 


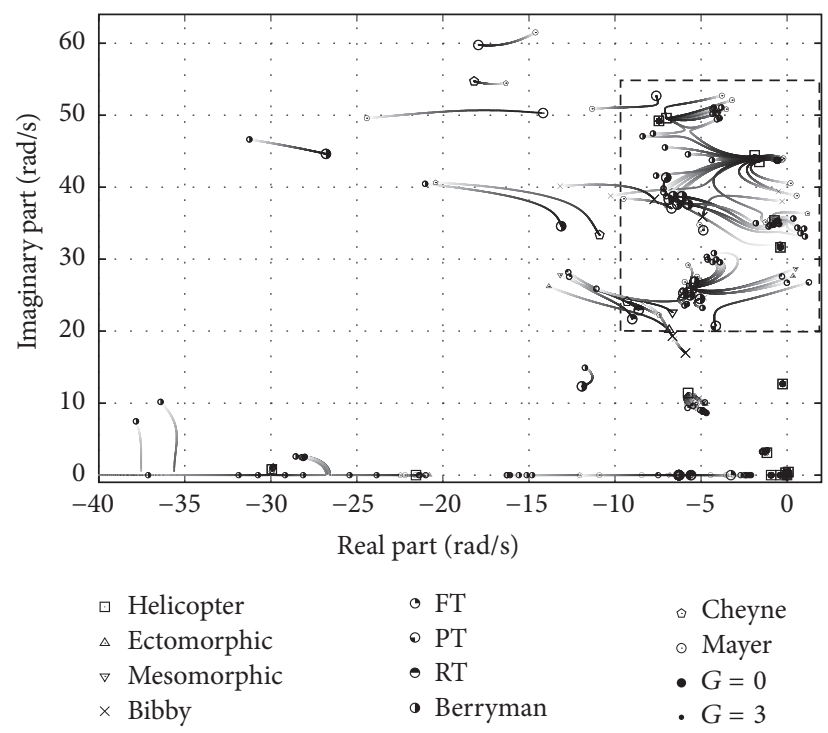

FIGURE 6: Collective control pilot-in-the-loop root loci, for gearing ratio increase. The area delimited by dashed rectangle is that represented in Figure 7.

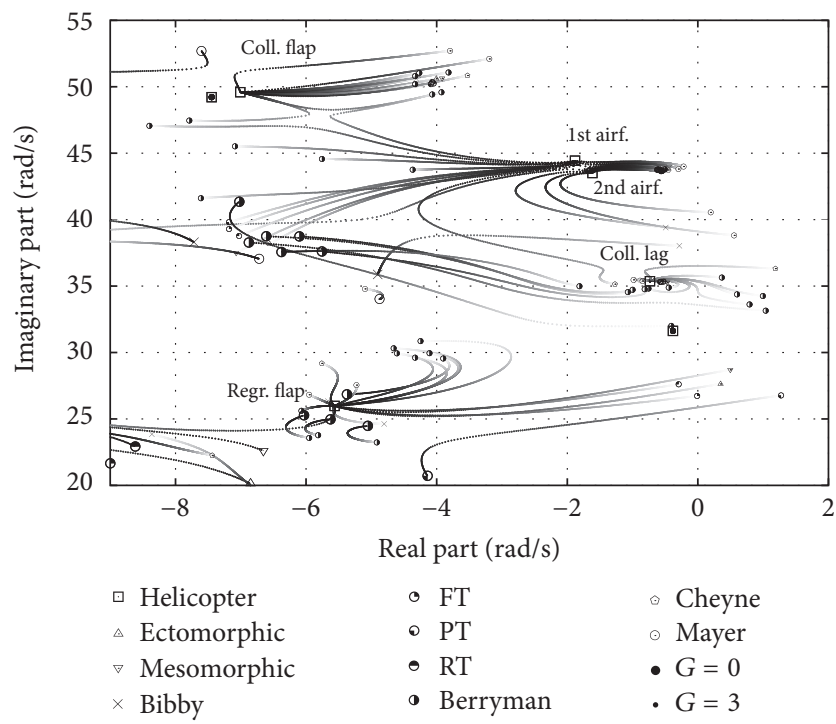

FIGURE 7: Collective control pilot-in-the-loop root loci, for gearing ratio increase, enlargement. The most relevant aeroelastic poles in $\mathrm{RPC}$ are indicated.

However, it is possible to draw some interesting considerations: In this scenario the task influence on pilot-helicopter closed-loop is present only in the BDFTs proposed in [20]; see Section 3.1. In that study, the authors concluded that the "position task" causes responses stronger than those from relax task (RT) and force task (FT), in the range of frequencies between 2 and $3 \mathrm{~Hz}$. That behavior seems to be due to the stiffer response of the pilot when instructed to maintain the position of the control stick. Such effect affects the whole system, as shown in Figure 6 where the poles obtained using

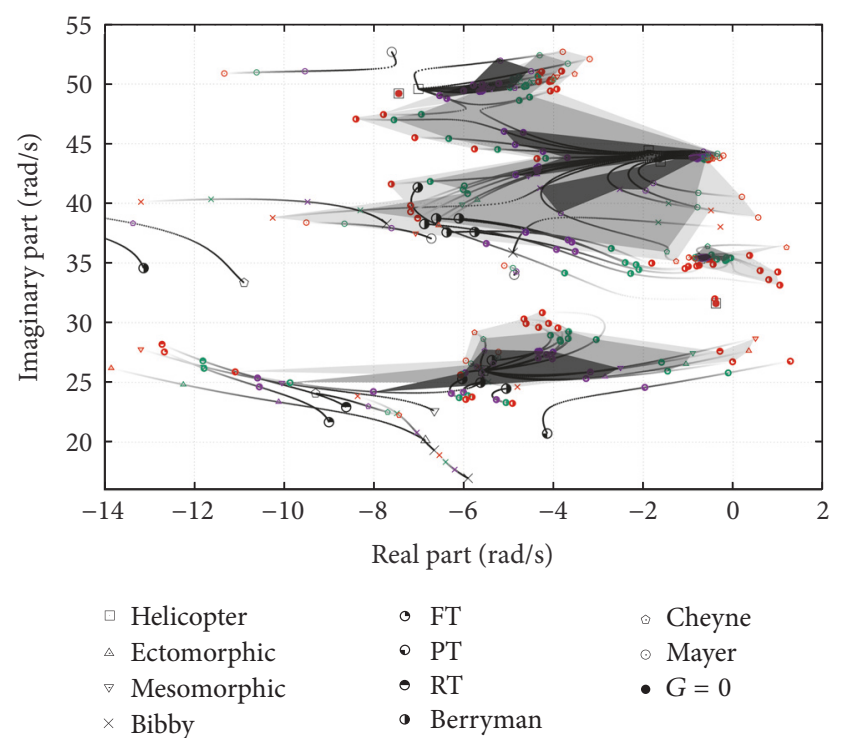

FIGURE 8: Areas delimited by root loci, for $G=1$ (violet), 2 (green), and 3 (red).

PT-BDFT are more prone to became unstable with respect to those obtained by RT-BDFT or FT-BDFT. Similar deduction can be drawn considering the effect of Mayo's ectomorphic and mesomorphic pilot transfer function on the closed-loop stability. Both models give similar root loci, coherently with the fact that the tasks in the experiments were the same. It is worth reminding that Mayo's models take also into account the effect of arm position (through the coefficient $G$ shown in Figure 4). However, that coefficient is determined once the linearization condition is set.

Other general considerations that may be drawn are as follows:

(i) Pilot in the loop significantly affects most of the aeroelastic poles of the helicopter in the $2-10 \mathrm{~Hz}$ frequency range, confirming that above this range no significant couplings arise (however, it is worth noting that also noncritical low-frequency poles are significantly affected).

(ii) While some aeroelastic poles show a well-defined behavior with the increase of gearing ratio, in other cases the behavior is more erratic: this suggests the need of a robust approach to PAO analysis.

(iii) The stability of some poles is strongly affected by the pilot model considered: for example, some poles become unstable only when a subset of pilots is considered.

(iv) The airframe elastic modes, the collective and regressive flap, and the collective lag blade modes are those most involved in collective bounce RPC. This is due both to their frequency (between 2 and $8 \mathrm{~Hz}$, i.e., in the range of passive pilot actions) and to the fact that the corresponding modal shapes are strongly coupled with collective control and vertical motion. 

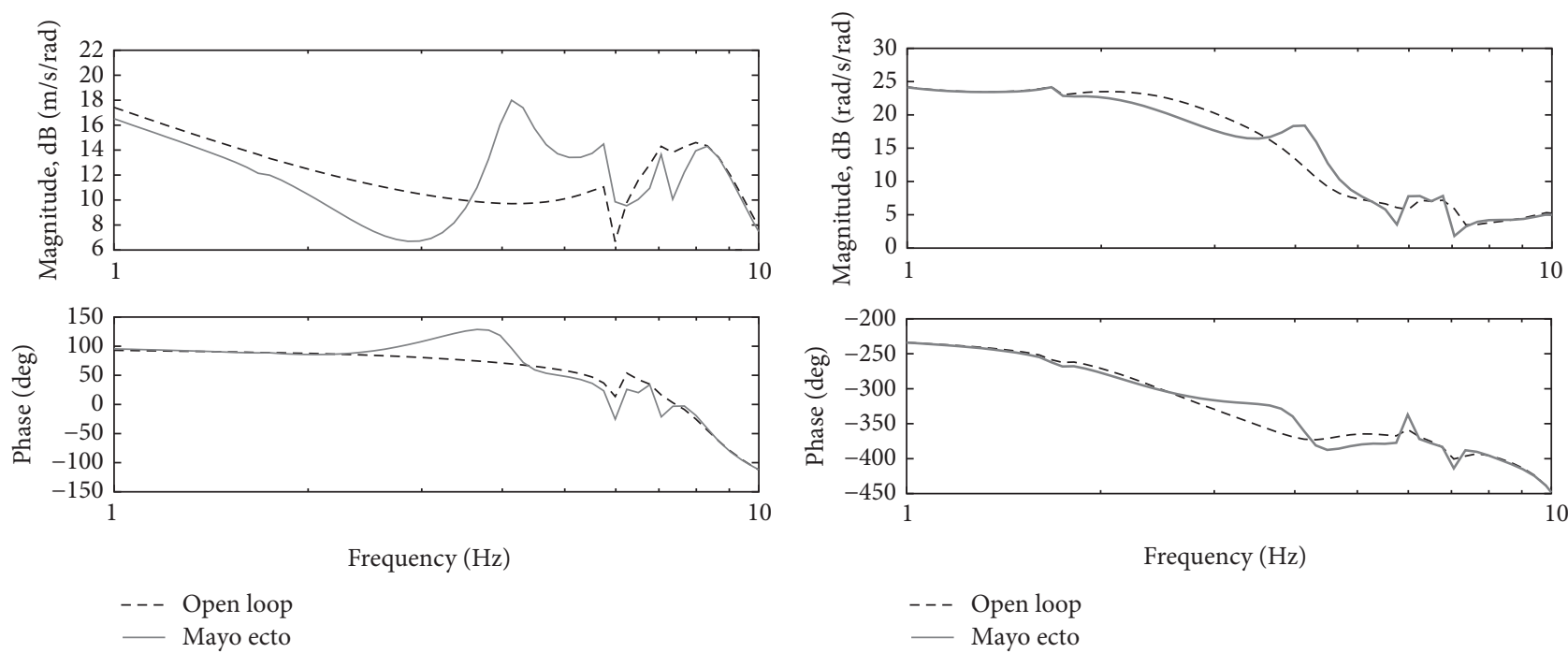

(a) $w$ versus $\theta_{0}$

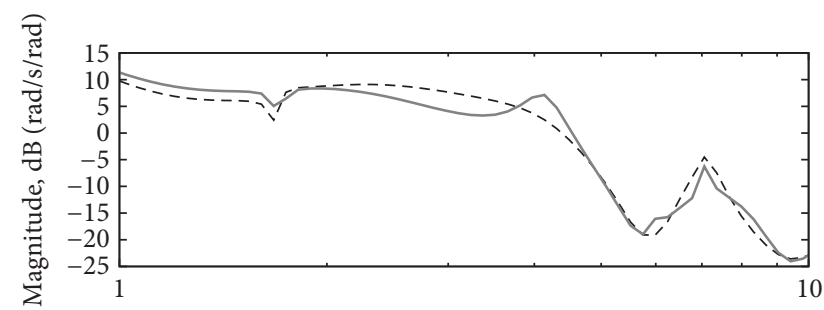

(b) $p$ versus $\theta_{c}$

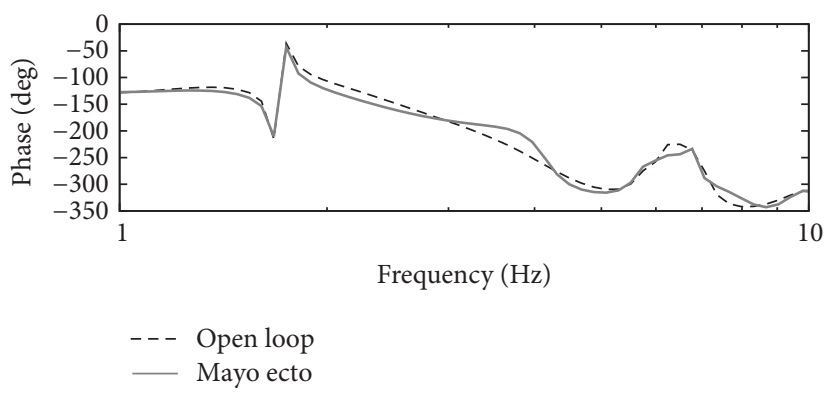

(c) $q$ versus $\theta_{s}$
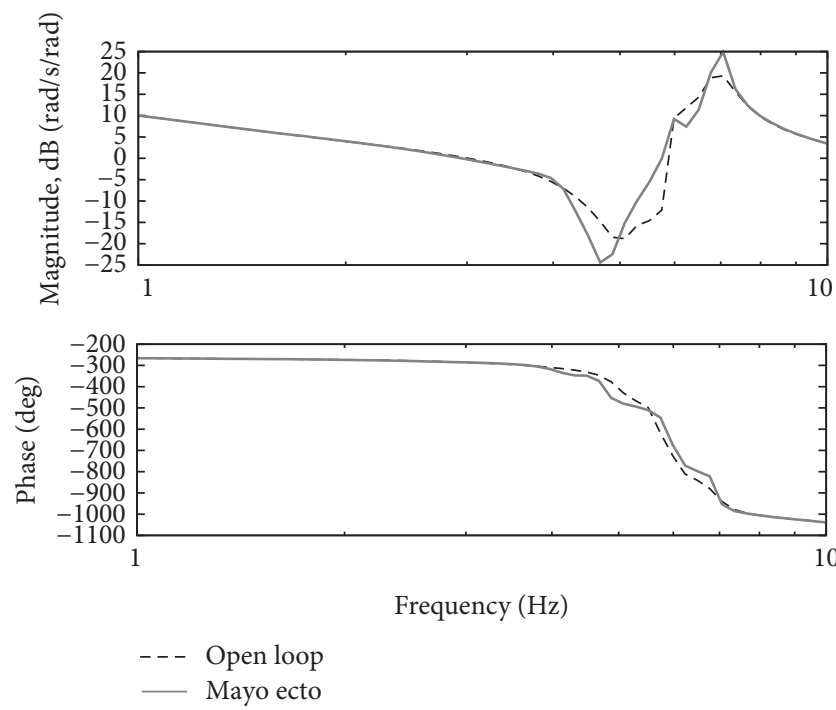

(d) $r$ versus $\theta_{p}$

FIGURE 9: Helicopter transfer functions for in-the-loop and out-of-the loop collective control pilot.

Considering in detail, for instance, Mayo's ectomorphic pilot model in the loop, its effects on the most representative helicopter transfer functions are provided in Figures 9(a)-9(d). As expected, the influence is bigger on $z$-axis response (Figure 9(a)). Moreover, coherently with results given in [32-34], Mayo's pilot reduces the magnitude of $w_{\theta_{0}}$ in the frequency range below its characteristic pole, while in its proximity it causes increase of vehicle response.

Finally, Figure 10 shows the range of variability of the transfer function $w$ versus $\theta_{0}$ with respect to the applied collective control pilot model, for $G=1.2$. As expected, the different number and positioning of collective pilot poles significantly modify the vertical response of the helicopter, in terms of both magnitude and phase. This is definitely true for model identified from different subjects responses and also for the models extracted from different tests performed by the same pilot (coherently with what has been obtained in terms of root loci).

Lateral Cyclic Pilot. Still considering a helicopter hovering condition, Figure 11 shows the root loci obtained changing the lateral control gearing ratio from 0 to 3 , with the pilot models described in Section 3.1.2 included in the loop. Also in this case, some common trends are observed, but a number of poles have a clearly scattered behavior. In particular, only some of the pilot models make one of the aeroelastic system poles unstable for $G$ approaching 2. Moreover, while collective pilots significantly affect only poles in the midfrequency range, the influence of lateral pilot extends to flight dynamics (low) frequencies.

Figure 12 represents the transfer functions more affected by the presence of lateral pilots models in the loop. The effect 

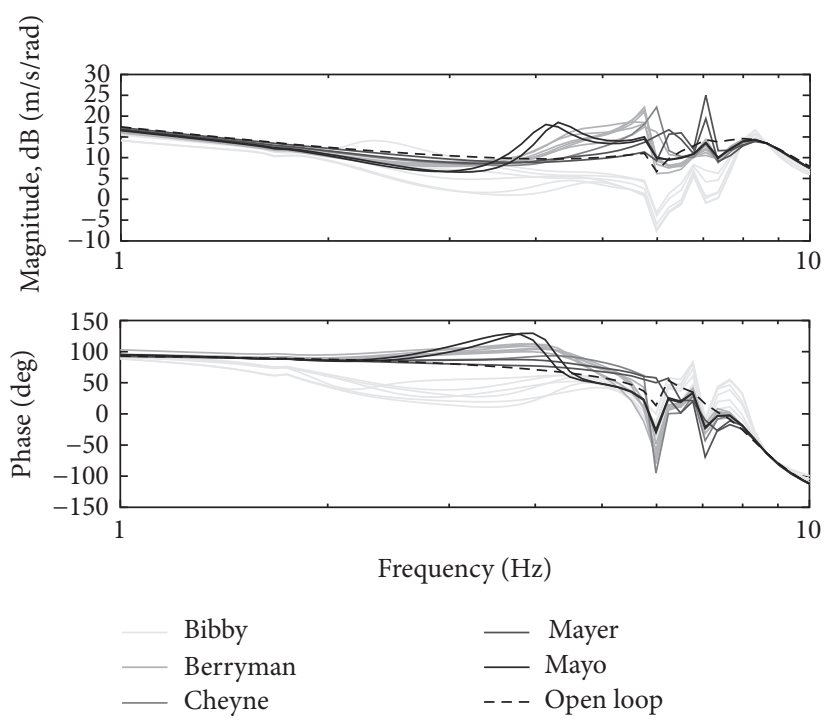

FIGURE 10: Influence on $w$ versus $\theta_{0}$ of different pilot models.

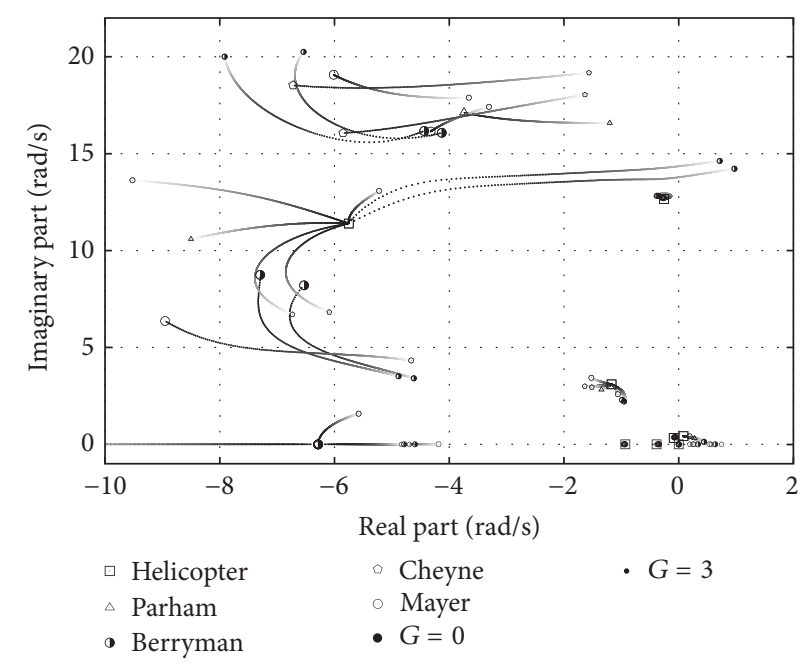

FIGURE 11: Lateral pilot-in-the-loop root loci, for gearing ratio increase.

of lateral pilots on helicopter dynamics is significantly smaller than that of vertical pilots but still appreciable, especially on lateral variables.

Finally, Figure 13 shows the influence of Parham's longitudinal pilot on lateral pilot-in-the-loop root loci. When lateral pilot is out of the loop, the poles of the fixed-control helicopter (thin squares) are significantly perturbed by the presence of longitudinal pilot (big squares, $G=1$ ), only below $1 \mathrm{~Hz}$. Comparing with Figures 11 and 13, it is possible to note that its influence is small also when lateral pilots enter the loop. In other words, couplings between the two pilot dynamics are negligible and longitudinal pilot is the least relevant for aeroelastic RPC analyses.

4.2. Active Pilot in the Loop. Concerning the examination of active pilot-in-the-loop effects, first the influence of different helicopter dynamics models, $Y_{c}$, on the definition of the crossover active pilot transfer function is assessed. To this purpose, three rotorcraft models have been considered: a simple SISO model for the vertical velocity, $w$,

$$
M \dot{w}+Z_{w} w=Z_{\theta_{0}} \theta_{0}
$$

a 6-DOF rigid-body model, and a more complex model including blade and airframe elasticity effects.

The corresponding transfer functions relating vertical response, $z$, to collective pitch, $\theta_{0}$, are presented in Figure 14, where it can be observed that the 1-DOF and 6-DOF models provide quite similar results, whereas the inclusion of the elastic-body effects particularly affects the mid/high frequency range (above $10 \mathrm{~Hz}$ ). The phase plot presents relevant differences between results from rigid and aeroelastic models 

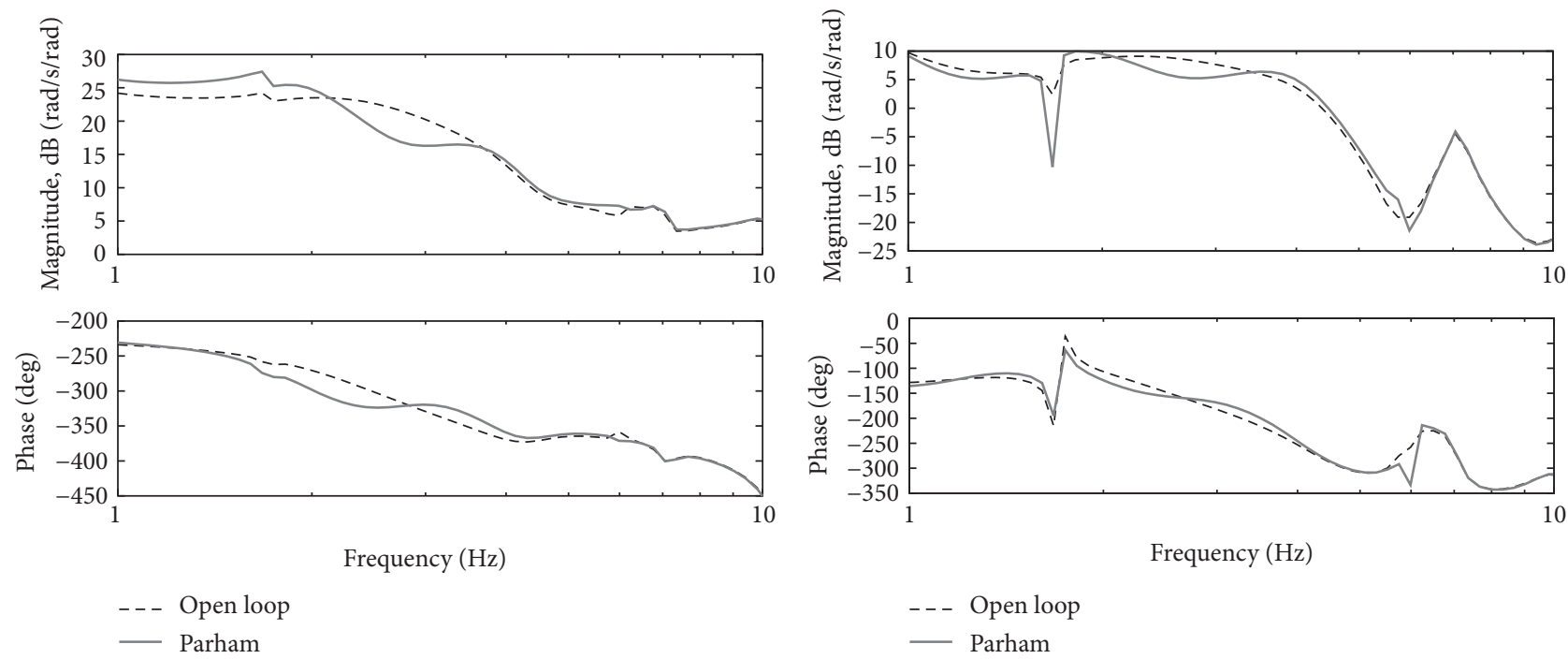

(a) $p$ versus $\theta_{c}$
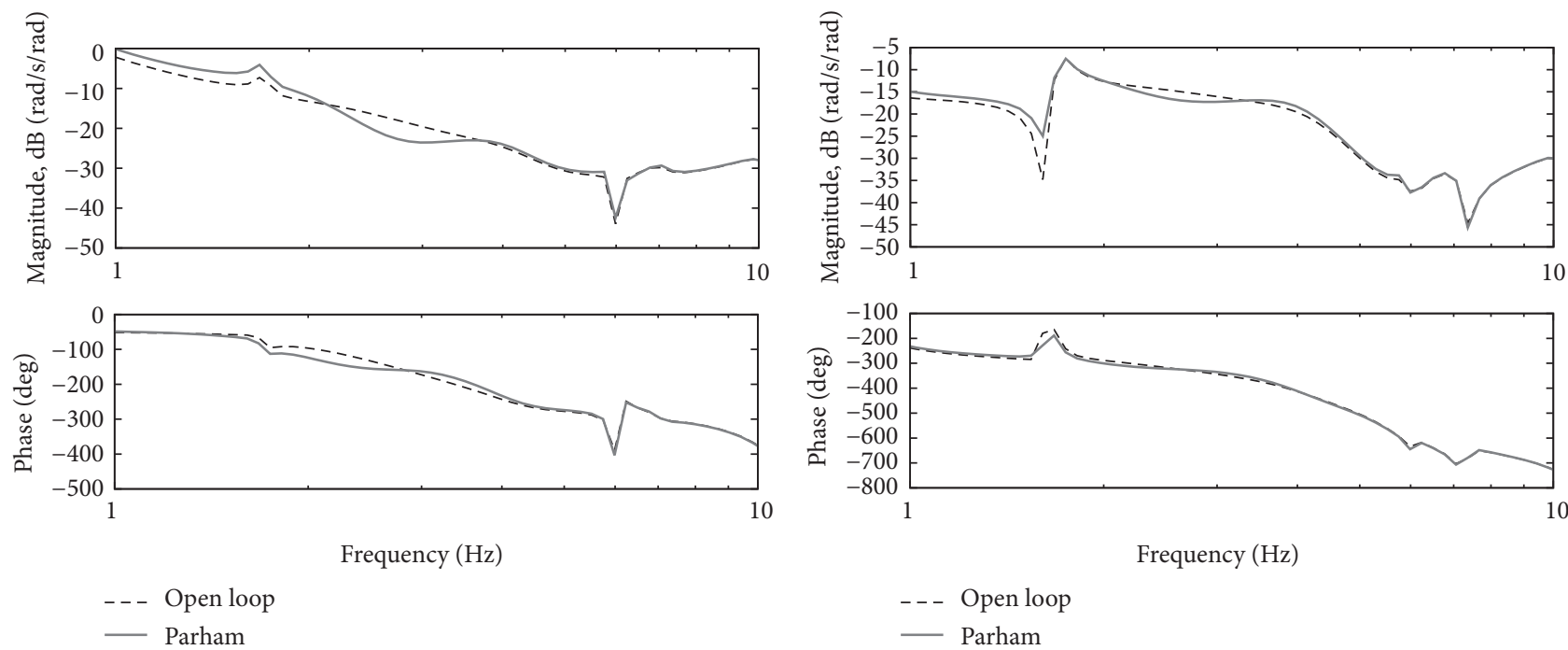

(c) $v$ versus $\theta_{c}$

(d) $u$ versus $\theta_{s}$

FIgURE 12: Helicopter transfer functions for in-the-loop and out-of-the loop lateral control pilot.

one also in proximity of $0.1 \mathrm{~Hz}$ (due to the low-frequency blade flapping dynamics effects). At high frequency, where the rigid response is dominated by inertial terms, the two rigid models become practically coincident.

The crossover pilot transfer functions derived from these helicopter models are depicted in Figure 15. Since active piloting actually affects low-frequency range dynamics $(4 \pi \mathrm{rad} / \mathrm{s}$ is a commonly accepted upper boundary), the crossover model has been modified by introducing two Butterworth filters in order to avoid nonphysical high frequency pilot response.

Figures 16 and 17 show the different helicopter spectral response resulting from the application of the three active pilot models depicted in Figure 15. Although the overall root loci are quite similar, significant discrepancies arise in terms of stability margin (low-frequency poles), with the active pilot based on "elastic" rotorcraft model bringing to instability for gearing ratio $30 \%$ lower than that occurring for instability when $Y_{c}$ consists of the simplest "1-DOF" rotorcraft model.

Note that, because of the inversion of the helicopter dynamics, $Y_{c}(s)$, required in (8) to determine the pilot transfer function, $Y_{p}(s)$, particular attention must be paid to the application of crossover pilot models based on vehicle dynamics characterized by zeros with positive real parts (nonminimum phase, stable systems), in that these would introduce unstable pilot poles.

\section{Conclusions}

Several pilot models have been examined for pilot-in-theloop helicopter aeromechanics analysis. These have been 


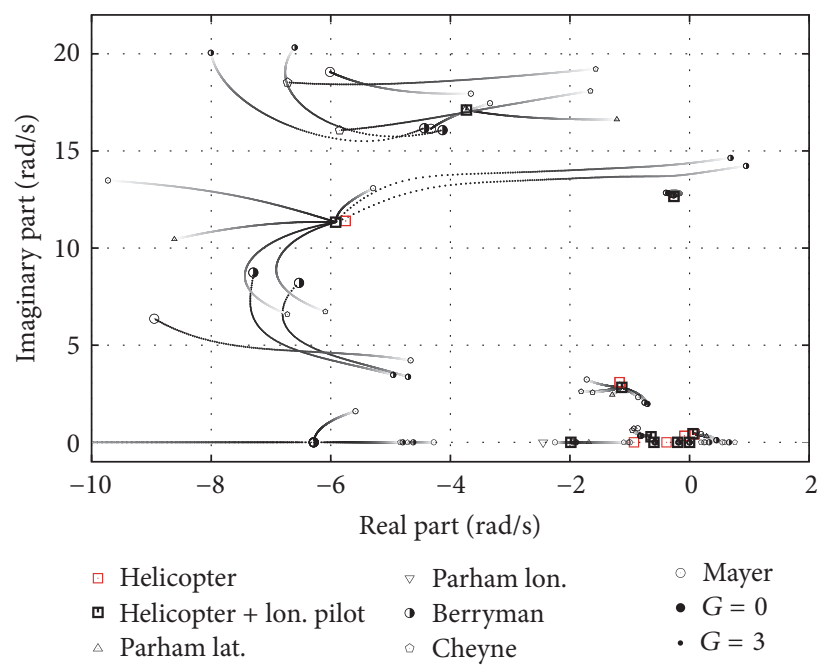

Figure 13: Effects of longitudinal pilot-in-the-loop on root loci, for gearing ratio increase.
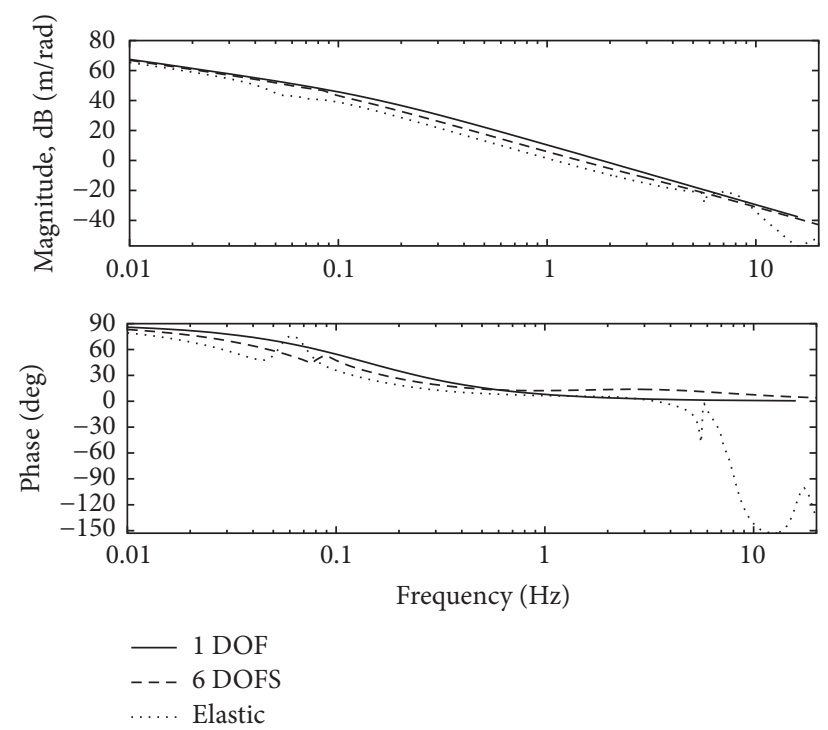

FIGURE 14: Transfer functions $z$ versus $\theta_{0}$ from different helicopter modeling.

selected form the literature produced in the last 30 years and include collective, lateral, and longitudinal controls, as well as active and passive pilot behavior. The focus has been on the sensitivity of helicopter responses to pilot model variation (due to its intrinsic uncertainties), with particular attention on the aeromechanical stability of a lightweight helicopter. The investigation has highlighted several critical issues which may be summarized as follows:

(i) Passive pilot transfer functions on collective and lateral cyclic controls vary from pilot to pilot employed in the identification tests and depend on the specific pilot task considered. Literature provides several models which are often reported after averaging a number of tests. The observed considerable high
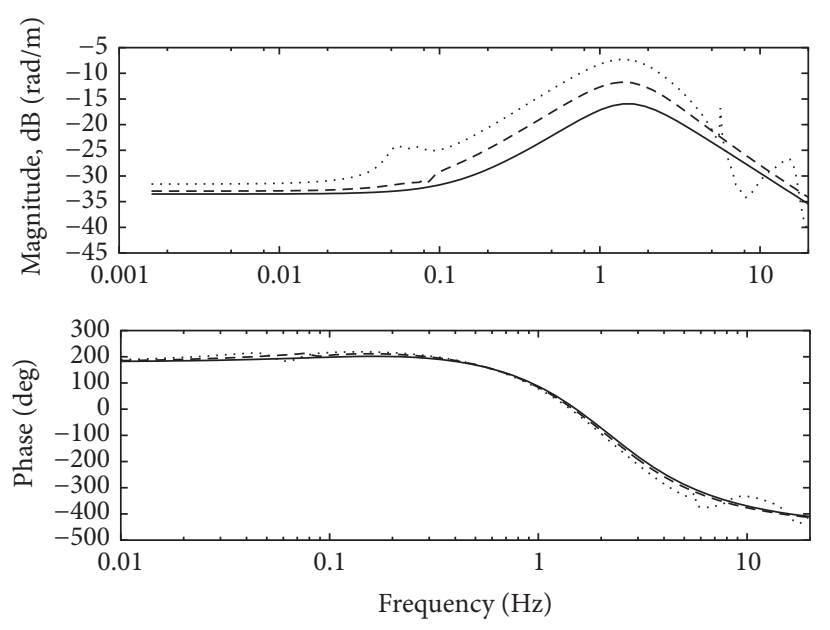

$$
\begin{array}{ll}
- & 1 \text { DOF } \\
--- & 6 \text { DOFS } \\
\ldots . . & \text { Elastic }
\end{array}
$$

FIGURE 15: Active pilot models obtained using machine dynamics shown in Figure 14.

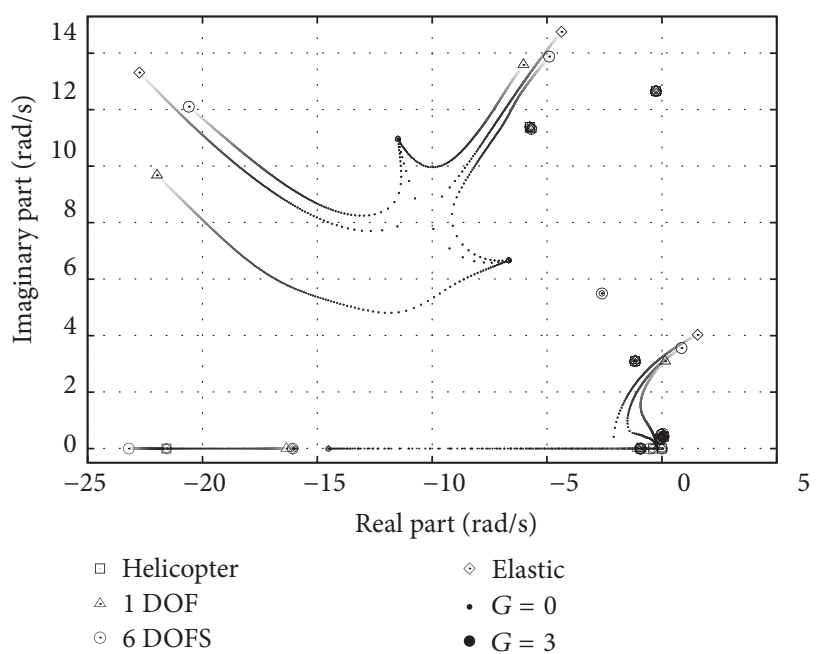

FIGURE 16: Influence of helicopter dynamic modeling on active pilot in the loop.

corresponding variance of the pilot-in-the-loop helicopter aeromechanic response suggests the search of a more robust modeling approach.

(ii) Helicopter dynamics are appreciably affected by lateral pilot responses and scarcely affected by longitudinal ones; couplings between longitudinal and lateral pilot responses are negligible.

(iii) The influence of the crossover active pilot model on helicopter dynamics is significantly affected by the rotorcraft model used in its definition; furthermore, critical responses are achieved when this model is represented by a transfer function with a real, positive zero. 


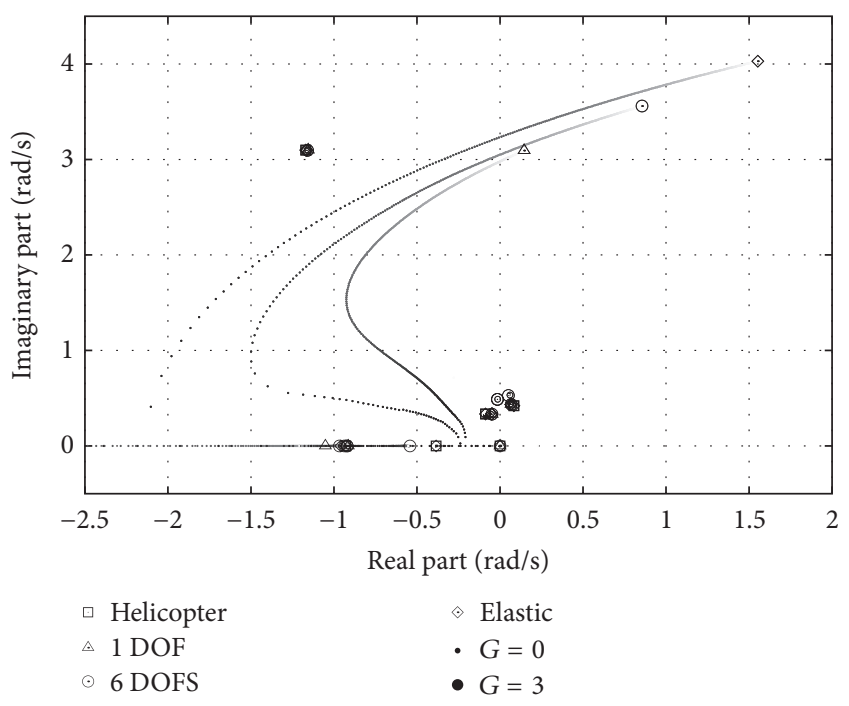

FIGURE 17: Influence of helicopter dynamic modeling on active pilot in the loop, enlargement.

\section{Conflicts of Interest}

The authors declare that there are no conflicts of interest regarding the publication of this paper.

\section{References}

[1] D. G. Mitchell and D. H. Klyde, "Recommended practices for exposing pilot-induced oscillations or tendencies in the development process," in Proceedings of the USAF Developmental Test and Evaluation Summit, AIAA 2004-6810, Woodland Hills, Calif, USA, November 2004.

[2] Aircraft Accident Investigation Commission, "Japan Airlines flight 706 McDonnell Douglas MD-11 JA8580 over Shima peninsula, Japan, 8 June 1997," Tech. Rep. TR-99-8, Ministry of Transport, 1999.

[3] D. G. Mitchell and D. H. Klyde, "Identifying a PIO signature-new techniques applied to an old problem," JAL 1500:11, 2006.

[4] D. T. McRuer, Aviation Safety and Pilot Control: Understanding and Preventing Unfavorable Pilot-Vehicle Interactions, National Research Council, National Academy Press, Washington, DC, USA, 1997.

[5] I. L. Ashkenas, H. R. Jex, and D. T. McRuer, "Pilot-induced oscillations: their cause and analysis," Tech. Rep., DTIC Document, 1964.

[6] R. D. Connor, "Wrecked rotors: understanding rotorcraft accidents, 1935-1945," in Proceedings of the American Helicopter Society 66th Annual Forum, Phoenix, Ariz, USA, May 2010.

[7] J. R. Mayo, "The involuntary partecipation of a human pilot in a helicopter collective control loop," in Proceedings of the 15th European Rotorcraft Forum, Association Industrie Aerospaziali, Amsterdam, The Netherlands, September 1989.

[8] T. Parham, "V-22 pilot-in-the-loop aeroelastic stability analysis," in Proceedings of the 47th American Helicopter Society Annual Forum, pp. 1307-1319, Phoenix, Ariz, USA, May 1991.
[9] T. Parham, "Aeroelastic and aeroservoelastic stability of the BA 609," in Proceedings of the 25th European Rotorcraft Forum, Rome, Italy, September 1999.

[10] M. D. Pavel, M. Jump, B. Dang-Vu et al., "Adverse rotorcraft pilot couplings-past, present and future challenges," Progress in Aerospace Sciences, vol. 62, pp. 1-51, 2013.

[11] M. Gennaretti, J. Serafini, P. Masarati, and G. Quaranta, "Effects of biodynamic feedthrough in rotorcraft/pilot coupling: collective bounce case," Journal of Guidance, Control, and Dynamics, vol. 36, no. 6, pp. 1709-1721, 2013.

[12] J. Serafini, M. M. Colella, and M. Gennaretti, "A finite-state aeroelastic model for rotorcraft-pilot coupling analysis," CEAS Aeronautical Journal, vol. 5, no. 1, pp. 1-11, 2014.

[13] G. Quaranta, A. Tamer, V. Muscarello et al., "Rotorcraft aeroelastic stability using robust analysis," CEAS Aeronautical Journal, vol. 5, no. 1, pp. 29-39, 2014.

[14] M. D. Pavel, P. Masarati, M. Gennaretti et al., "Practices to identify and preclude adverse Aircraft-and-Rotorcraft-Pilot Couplings-a design perspective," Progress in Aerospace Sciences, vol. 76, pp. 55-89, 2015.

[15] D. T. McRuer and E. S. Krendel, "Mathematical models of human pilot behavior," Tech. Rep., DTIC Document, 1974.

[16] M. M. Lone and A. K. Cook, "Review of pilot modelling techniques," in Proceedings of the 48th AIAA Aerospace Sciences Meeting Including the New Horizons Forum and Aerospace Exposition, Orlando, Fla, USA, January 2010.

[17] D. Yilmaz, M. Jump, L. Linghai, and M. Jones, "State-of-theart pilot model for RPC prediction report," ARISTOTEL EU Project, ACPOGA-2010-266073, Technical Report D2.3, 2011.

[18] R. A. Hess, "Modeling biodynamic interference in helicopter piloting tasks," in Proceedings of the AHS Aeromechanics Specialists Conference, pp. 496-504, January 2010.

[19] P. Masarati, G. Quaranta, and M. Jump, "Experimental and numerical helicopter pilot characterization for aeroelastic rotorcraft-pilot coupling analysis," Proceedings of the Institution of Mechanical Engineers Part G: Journal of Aerospace Engineering, vol. 227, no. 1, pp. 125-141, 2013.

[20] J. Venrooij, M. D. Pavel, M. Mulder, F. C. T. van der Helm, and H. H. Buülthoff, "A practical biodynamic feedthrough model for helicopter," CEAS Aeronautical Journal, vol. 4, no. 4, pp. 421432, 2014.

[21] L. Zaichik, P. Desyatnik, Y. Yashin et al., "Pilot modelling for aero-servo-elastic A/RPC," ARISTOTEL EU Project, ACPOGA-2010-266073, Technical Report D3.6, 2013.

[22] P. Masarati and G. Quaranta, "Bioaeroservoelastic analysis of involuntary rotorcraft-pilot interaction," Journal of Computational and Nonlinear Dynamics, vol. 9, no. 3, Article ID 031009, 2014.

[23] W. A. Kuczynski, D. E. Copper, W. J. Twomey, and J. J. Howlett, "Influence of engine/fuel control design on helicopter dynamics and handling qualities," Journal of the American Helicopter Society, vol. 25, no. 2, pp. 26-34, 1980.

[24] M. Mattaboni, A. Fumagalli, M. Jump, P. Masarati, and G. Quaranta, "Biomechanical pilot properties identification by inverse kinematics/inverse dynamics multibody analysis," in Proceedings of the 26th Congress of International Council of the Aeronautical Sciences (ICAS '08), pp. 3684-3698, September 2008.

[25] A. Tustin, "An investigation of the operators response in manual control of a power-driven gun," CS Memorandum 169, 1944. 
[26] K. B. Zaychik, F. M. Cardullo, and G. George, "A conspectus on operator modeling: past, present and future," AIAA Paper 6625:2006, 2006.

[27] R. Heffley, "Use of a task-pilot-vehicle (TPV) model as a tool for flight simulator math model development," in Proceedings of the AIAA Guidance, Navigation, and Control Conference, Toronto, Canada, August 2010.

[28] M. M. Lone, N. Ruseno, and A. K. Cooke, "Towards understanding effects of non-linear flight control system elements on inexperienced pilots," Aeronautical Journal, vol. 116, no. 1185, pp. 1201-1206, 2012.

[29] R. A. Hess, "Unified theory for aircraft handling qualities and adverse aircraft-pilot coupling," Journal of Guidance, Control, and Dynamics, vol. 20, no. 6, pp. 1141-1148, 1997.

[30] R. Hosman and H. Stassen, "Pilot's perception in the control of aircraft motions," Control Engineering Practice, vol. 7, no. 11, pp. 1421-1428, 1999.

[31] W. Johnson, Helicopter Theory, Courier Corporation, 2012.

[32] J. Serafini, D. Muro, and M. Gennaretti, "Pilot-in-the-loop influence on controlled tiltrotor stability and gust response," in Proceedings of the 27th International Congress of the Aeronautical Sciences, Nice, France, 2010.

[33] D. Muro, M. M. Colella, J. Serafini, and M. Gennaretti, "An optimal control approach for alleviation of tiltrotor gust response," Aeronautical Journal, vol. 116, no. 1180, pp. 651-666, 2012.

[34] J. Serafini, L. Greco, and M. Gennaretti, "Rotorcraft-pilot coupling analysis through state-space aerodynamic modelling," Aeronautical Journal, vol. 119, no. 1219, pp. 1105-1122, 2015. 


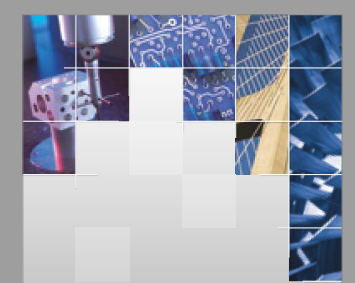

\section{Enfincering}
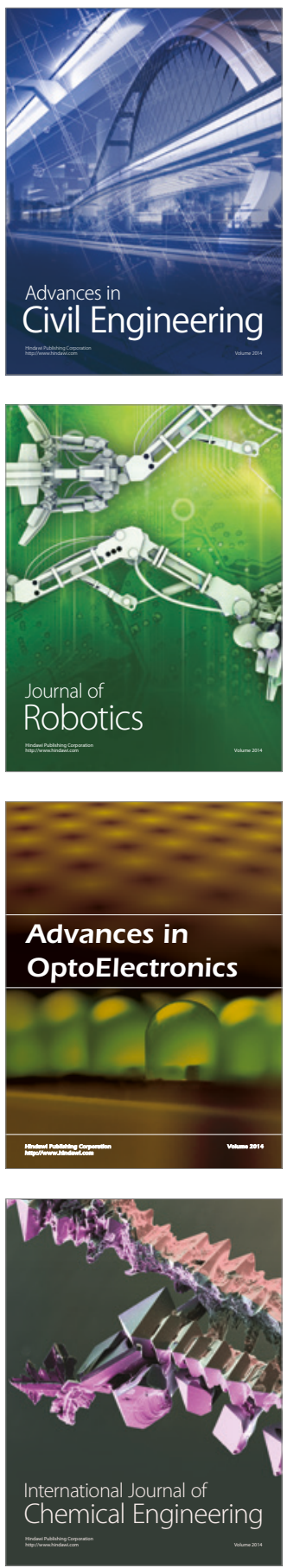

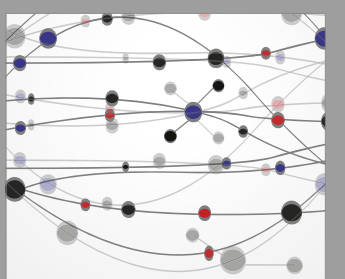

The Scientific World Journal

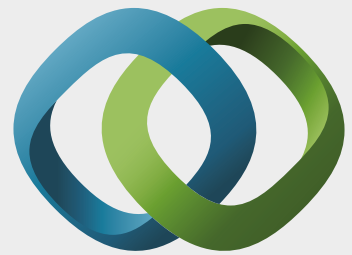

\section{Hindawi}

Submit your manuscripts at

https://www.hindawi.com
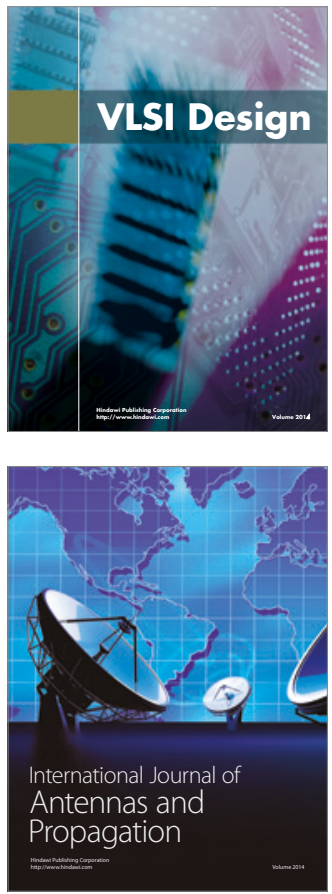

\section{Rotating}

Machinery
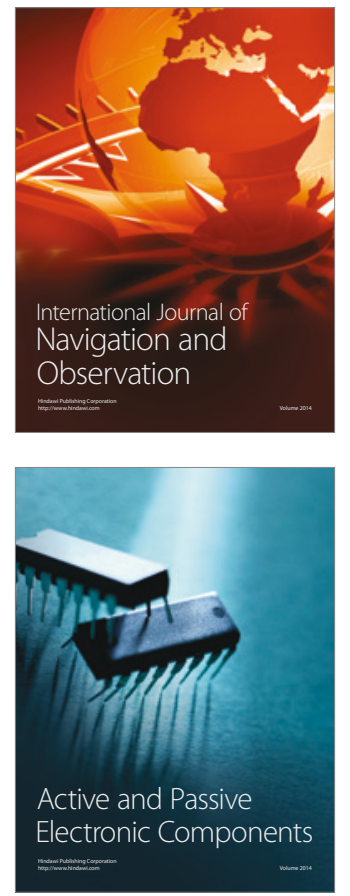
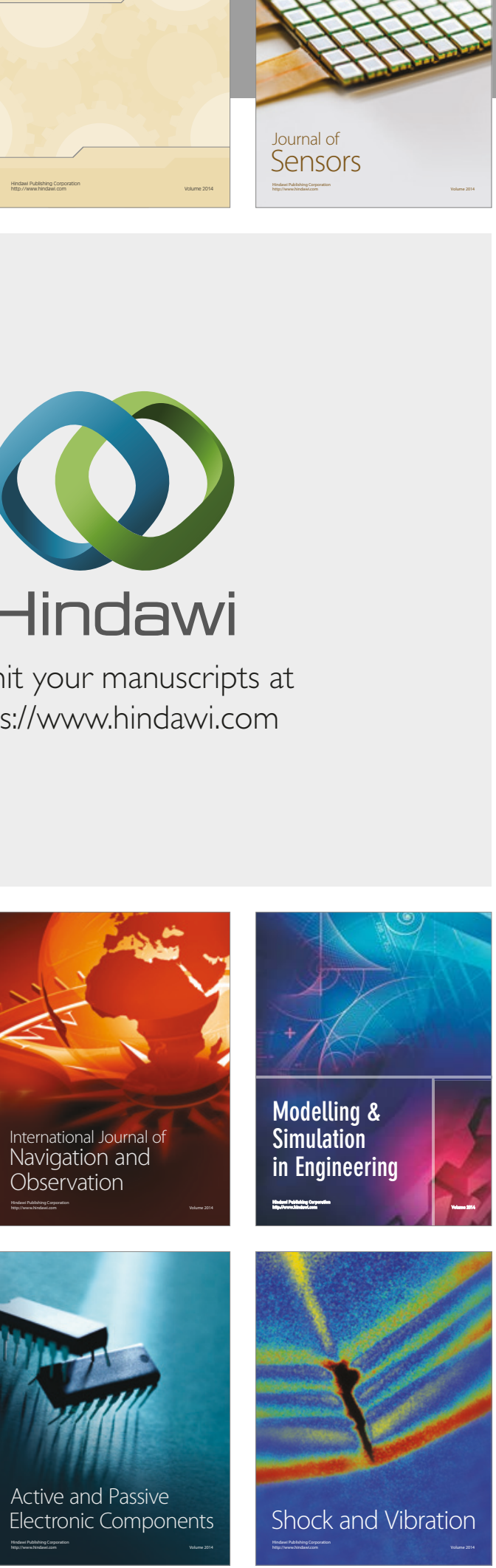
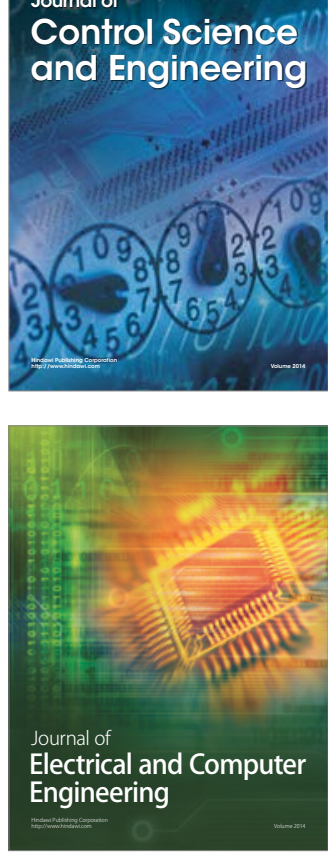

Distributed

Journal of

Control Science

and Engineering
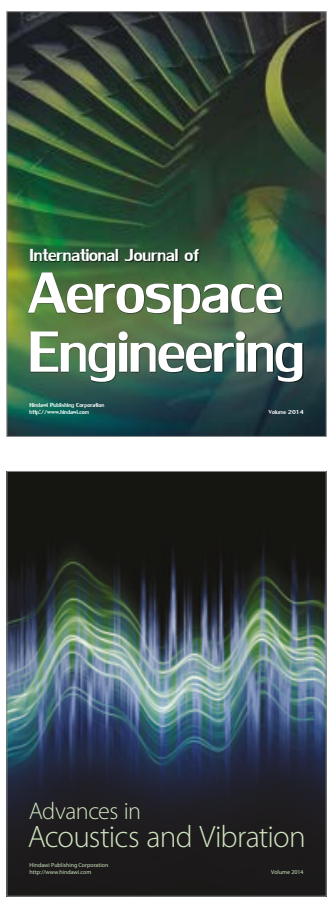

Sensor Networks 